\title{
Dynamic analysis of a pumped-storage hydropower plant with random power load
}

\author{
Hao Zhang ${ }^{1}$, Diyi Chen ${ }^{1}$, Beibei Xu ${ }^{1}$, Edoardo Patelli ${ }^{2}$, Silvia Tolo ${ }^{2}$ \\ ${ }^{1}$ Institute of Water Resources and Hydropower Research, Northwest A\&F University, \\ Shaanxi Yangling, 712100 China \\ ${ }^{2}$ Institute of Risk and Uncertainty, University of Liverpool, Liverpool, United \\ Kingdom
}

\section{Corresponding author: Diyi Chen}

Mailing Address: Institute of Water Resources and Hydropower Research, Northwest A\&F University, Shaanxi Yangling 712100, China

Telephones: 086-181-6198-0277

E-mail: diyichen@,nwsuaf.edu.cn

\begin{abstract}
This paper analyzes the dynamic response of a pumped-storage hydropower plant in generating mode. Considering the elastic water column effects in the penstock, a linearized reduced order dynamic model of the pumped-storage hydropower plant is used in this paper. As the power load is always random, a set of random generator electric power output is introduced to research the dynamic behaviors of the pumped-storage hydropower plant. Then, the influences of the PI gains on the dynamic characteristics of the pumped-storage hydropower plant with the random power load are analyzed. In addition, the effects of initial power load and PI parameters on the stability of the pumped-storage hydropower plant are studied in depth. All of the above results will provide theoretical guidance for the study and
\end{abstract}


analysis of the pumped-storage hydropower plant.

Keywords: pumped-storage hydropower plant, dynamic characteristics, random load, mathematical modeling

\section{Introduction}

Pumped-storage hydropower plants (PSHP) play an important role in the peak regulation and frequency control of a power grid. They pump water with the power consumption at valley hours and generate electricity with the power consumption at peak hours to balance energy production and consumption levels [1-5]. As the PSHP can assume advantageously the power-frequency regulation, they allow power plant owners to improve the power supply quality effectively [6-10]. Therefore, the research on dynamic analysis and stability of the PSHP is of great importance.

Many studies focus on the modeling and dynamic analysis of the PSHP [11-16]. It is worth mentioning the work presented in Ref. [17] where the dynamic characteristics of a pump-turbine were studied. The dynamic method was proposed to simulate the critical transient parameters. In Ref. [18], the authors explored the nonlinear dynamic behaviors of a hydro-turbine governing system in the process of sudden load increase transient. In Ref. [19], a one-dimensional numerical code estimating the performances of centrifugal PATs (pumps used as turbines) was presented. The work of [20] is aimed to analyze the different guide-vane closing schemes for reducing the maximum transient pressures in the S-shaped region. A series of model tests were conducted on a pumped-storage station model and the measured data fully validated the correctness of the analyses.

In practical situations, it is difficult to regulate and control perfectly the dynamic characteristics of the PSHP because of the random power load [21-25]. In addition, the lack of the accurate model of the PSHP and the qualitative analysis of control parameters also make it hard to ensure the stable operation of the PSHP [26-28]. However, few researchers have focused on the dynamic characteristics of the PSHP with random power load. Therefore, to overcome the above situations, this paper tries to investigate the influences of the PI gains on the PSHP with the random load from 
the view point of dynamics. In addition, the effects of the initial load on the dynamic characteristic of the PSHP with random power load are analyzed deeply by means of simulations.

The remaining content of this paper is organized as follows. Section 2 introduces the PSHP. Section 3 presents the linear reduced order model of the PSHP. In Section 4, the system dynamic response is analyzed by means of simulations. The effects of the PI gains and initial power load on the dynamic characteristics of PSHP are discussed. Finally, Section 5 condenses the conclusions.

\section{Dynamical model of the PSHP}

The scheme of the considered system, corresponding to the mechanical and hydraulic components of the hydropower plant, is represented in Fig. 1. The main model blocks are described in the following subsections.

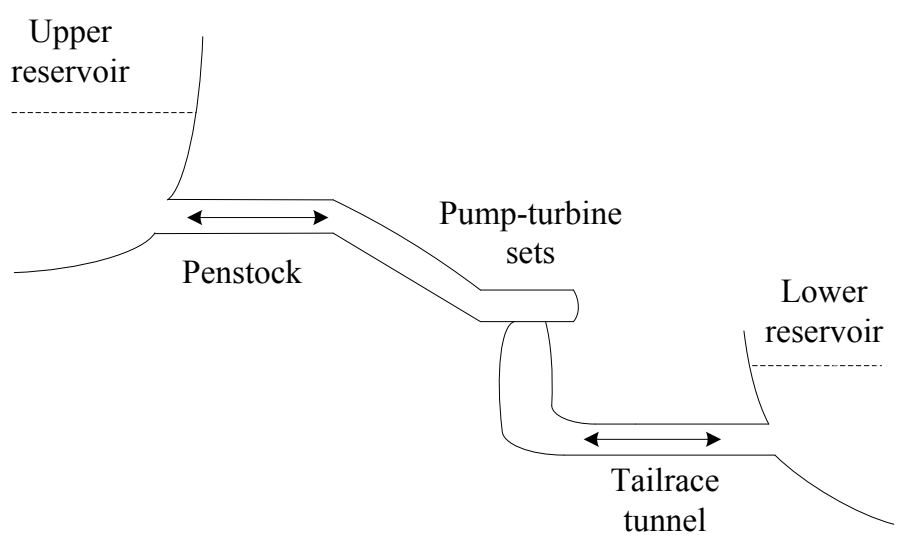

Fig. 1. Scheme of the dynamic model.

Notation

$b_{11}, b_{12}$, partial derivatives of the flow with respect to the head, speed and wicket

$b_{13} \quad$ gate position (p.u.)

$b_{21}, b_{22}$, partial derivatives of the turbine torque with respect to the head, speed

$b_{23} \quad$ and wicket gate position (p.u.)

$c \quad$ turbine mechanical torque (p.u.) 


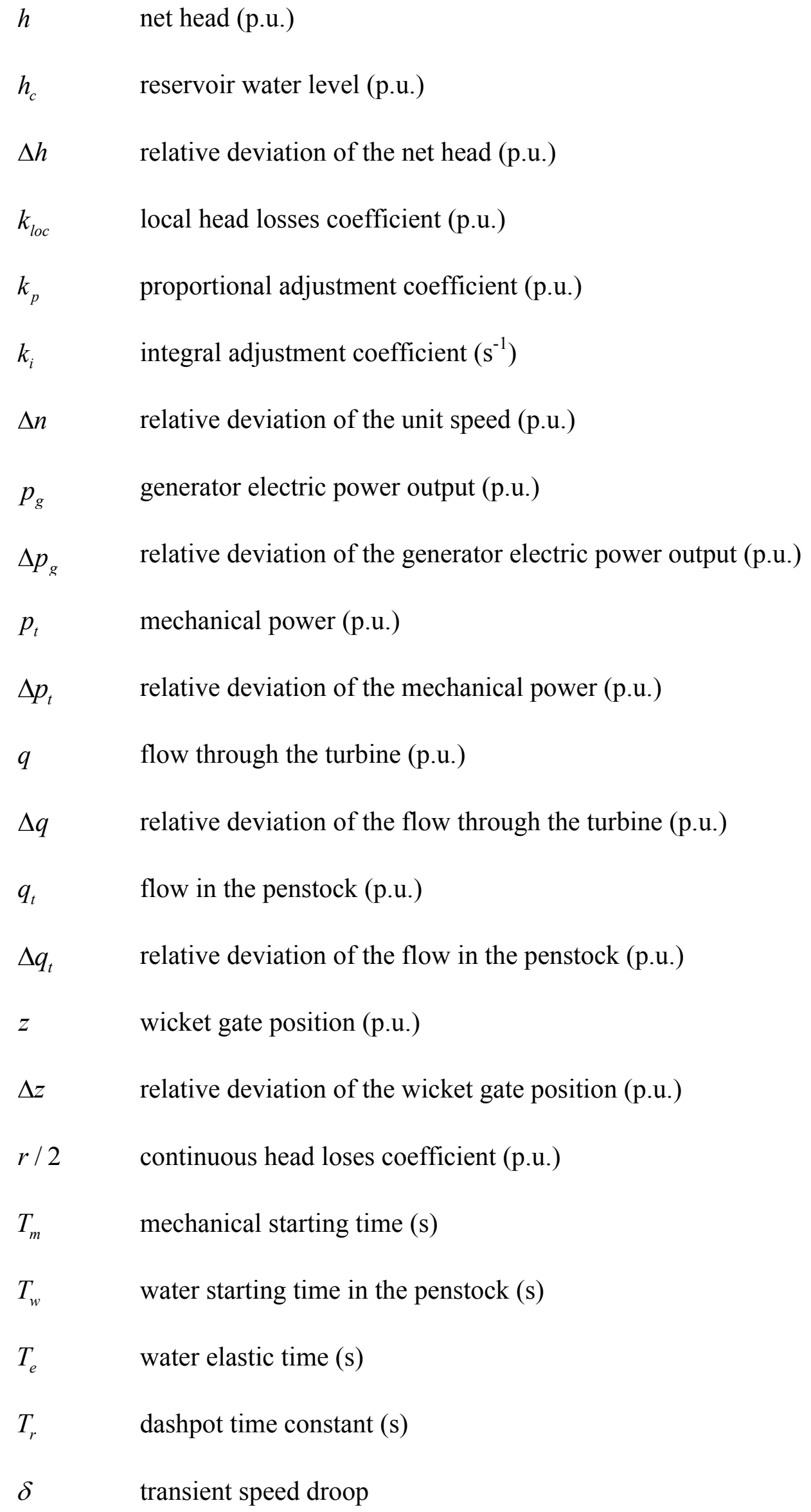


The speed variations caused by the unbalance between the relative deviation of generator power $\Delta p_{g}$ and relative deviation of mechanical power $\Delta p_{t}$ are presented as follows [29]:

$$
T_{m} \cdot \frac{d \Delta n}{d t} \cdot n=\Delta p_{t}-\Delta p_{g}
$$

Where $T_{m}$ is the mechanical starting time and $\Delta n$ indicates the relative deviation of unit speed.

A PI controller is used to eliminate the speed deviations. The controller gains are expressed as follows:

$$
\frac{1}{\delta} \cdot\left(1+\frac{1}{T_{r}} \int d t\right) \cdot \Delta n=\Delta z, k_{p}=\frac{1}{\delta} \text { and } k_{i}=\frac{1}{\delta T_{r}} .
$$

where $\delta$ and $T_{r}$ indicates the transient speed droop and dashpot time constant, respectively. $k_{p}$ and $k_{i}$ are the proportional adjustment coefficient and integral adjustment coefficient, respectively.

Note that:

$\Delta n=\left(n-n^{0}\right) / n^{0}, \Delta z=\left(z-z^{0}\right) / z^{0}$ are the relative deviations of unit speed and wicket gate position, respectively. Similarly, $\Delta q_{t}=\left(q_{t}-q_{t}^{0}\right) / q_{t}^{0}, \Delta q=\left(q-q^{0}\right) / q^{0}$, $\Delta h=\left(h-h^{0}\right) / h^{0}$ and $\Delta p_{t}=\left(p_{t}-p_{t}^{0}\right) / p_{t}^{0} \quad$ are the relative deviations of corresponding variables. The superscript ' 0 ' denotes the initial value.

\section{The linear reduced order model of the PSHP}

For control design purposes in plants with long penstocks, a reduced order penstock model is applied in this section [31]. The characteristic equations of the PSHP are linearized in the neighborhood of an initial equilibrium operating point in order to use linear methods for adjusting the controller gains [32].

A $\Pi$-shaped element having one series branch and two shunt branches is used here (Fig. 2). The total head losses are considered in the series branch and the 
elasticity effect is included in the shunt branches. The variations in the relative deviation of the reservoir water level $\Delta h_{c}$ are neglected and only the downstream shunt branch is involved in the plant dynamics. The series branch is represented by Eq. (3) and the shunt downstream branch by Eq. (4).

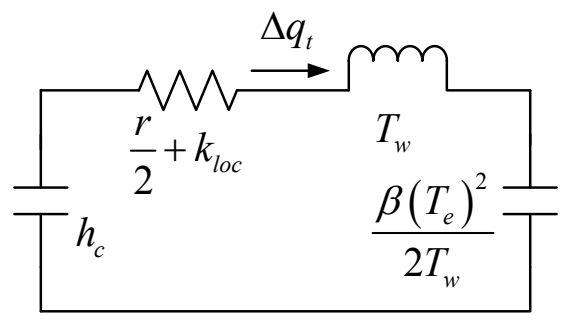

Fig. 2. Scheme of the penstock $\Pi$-shaped element model.

$$
\begin{gathered}
\frac{d \Delta q_{t}}{d t}=\frac{1}{T_{w}}\left(\Delta h_{c}-\Delta h-2\left(\frac{r}{2}+k_{l o c}\right) \Delta q_{t} q_{t}^{0}\right) \\
\frac{d \Delta h}{d t}=\frac{2 T_{w}}{\beta T_{e}^{2}}\left(\Delta q_{t}-\Delta q\right)
\end{gathered}
$$

where $\beta=\frac{8}{\pi^{2}} \cdot \frac{r}{2}$ and $k_{l o c}$ indicate the continuous head loses coefficient and local head losses coefficient, respectively. $T_{w}$ and $T_{e}$ are the water starting time in the penstock and water elastic time, respectively. From Ref. [11], the adequacy of the model has been verified.

The characteristic equations of the PSHP are Eqs. (1), (2), (3) and (4).

The linearized model of a hydro-turbine can be expressed as follows:

$$
\begin{aligned}
& \Delta q=b_{11} \Delta h+b_{12} \Delta n+b_{13} \Delta z \\
& \Delta c=b_{21} \Delta h+b_{22} \Delta n+b_{23} \Delta z
\end{aligned}
$$

and

$$
\Delta p_{t} \approx n^{0} \Delta c+c^{0} \Delta n=n^{0} b_{21} \Delta h+\left(n^{0} b_{22}+c^{0}\right) \Delta n+n^{0} b_{23} \Delta z
$$

The coefficients $b_{11}, b_{12}$ and $b_{13}$ are the partial derivatives of the flow with respect to the head, speed and wicket gate position, respectively; the coefficients $b_{21}$, $b_{22}$ and $b_{23}$ are the partial derivatives of the turbine torque with respect to the head, speed and wicket gate position, respectively. 
Neglecting second order terms in Eq. (1), the following expression can be obtained:

$$
\Delta p_{t}-\Delta p_{g}=T_{m} \cdot \frac{d \Delta n}{d t} \cdot\left(n^{0}+\Delta n\right) \approx T_{m} \cdot \frac{d \Delta n}{d t} n^{0}
$$

The following expression can be obtained by neglecting $\Delta h_{c}$ in Eq. (3):

$$
\frac{d \Delta q_{t}}{d t}=\frac{1}{T_{w}}\left(-\Delta h-2\left(\frac{r}{2}+k_{l o c}\right) q_{t}^{0} \Delta q_{t}\right)
$$

Finally, the plant model results in a 6th order dynamic system. The state equations are

$$
\left\{\begin{array}{l}
\frac{d \Delta n}{d t}=\frac{\Delta p_{t}-\Delta p_{g}}{T_{m} n^{0}} \\
\frac{d \Delta q_{t}}{d t}=-\frac{1}{T_{w}} \Delta h-\frac{2\left(\frac{r}{2}+k_{\text {loc }}\right)}{T_{w}} q_{t}^{0} \Delta q_{t} \\
\frac{d \Delta q}{d t}=b_{11}\left(\frac{\pi^{2} T_{w}}{4 T_{e}^{2}}\left(\Delta q_{t}-\Delta q\right)\right)+b_{12}\left(\frac{\Delta p_{t}-\Delta p_{g}}{T_{m} n^{0}}\right)+b_{13}\left(-k_{p}\left(\frac{\Delta p_{t}-\Delta p_{g}}{T_{m} n^{0}}\right)+k_{i} \Delta n\right) \\
\frac{d \Delta h}{d t}=\frac{\pi^{2} T_{w}}{4 T_{e}^{2}}\left(\Delta q_{t}-\Delta q\right) \\
\frac{d \Delta p_{t}}{d t}=n^{0} b_{21}\left(\frac{\pi^{2} T_{w}}{4 T_{e}^{2}}\left(\Delta q_{t}-\Delta q\right)\right)+\left(n^{0} b_{22}+c^{0}\right)\left(\frac{\Delta p_{t}-\Delta p_{g}}{T_{m} n^{0}}\right)+n^{0} b_{23}\left(-k_{p}\left(\frac{\Delta p_{t}-\Delta p_{g}}{T_{m} n^{0}}\right)+k_{i} \Delta n\right) \\
\frac{d \Delta z}{d t}=-k_{p}\left(\frac{\Delta p_{t}-\Delta p_{g}}{T_{m} n^{0}}\right)+k_{i} \Delta n
\end{array}\right.
$$

\section{Numerical experiment}

In this section, the effects of the PI gains and initial load on the dynamic characteristics of the PSHP are analyzed by means of the qualitative analysis. The numerical experiments are carried out by using the method of Runge-Kutta. More specifically, the fixed step is 0.1 . The initial values are $(0.001,0.001,0.001,0.001)$ and the iteration steps are 1000 .

In the daily operation of PSHP, the power load is subjected to a variety of random perturbations sustained in time, due to the dynamic behavior of consumption, temperature changes in the wires, errors in the measuring instruments, changes in the netwrok's topolopy, etc. Therefore, the randomness is present at all times, and it is necessary to descript it as faithfully as possible to analyze the stochastic behavior of 
real PSHP $[33,34]$. Considering the randomness of the power load, a set of Gaussian white noise (average $=0$, variance $=0.001$ ) generated by Matlab software as shown in Fig. 3 is introduced to simulate the random generator electric power.

The values of the plant parameters are included in Table 1.

\section{Table 1}

Turbine parameters and initial operation variables

\begin{tabular}{llllllll}
\hline$q^{0}$ & 1.0 & $n^{0}$ & 1.0 & $h^{0}$ & 1.0 & $z^{0}$ & 1.0 \\
$b_{11}$ & 0.5 & $b_{12}$ & 0.0 & $b_{13}$ & 1.0 & $T_{w}$ & $1.203 \mathrm{~s}$ \\
$b_{21}$ & 1.611 & $b_{22}$ & -1.556 & $b_{23}$ & 1.111 & $T_{e}$ & $5.029 \mathrm{~s}$ \\
\hline
\end{tabular}

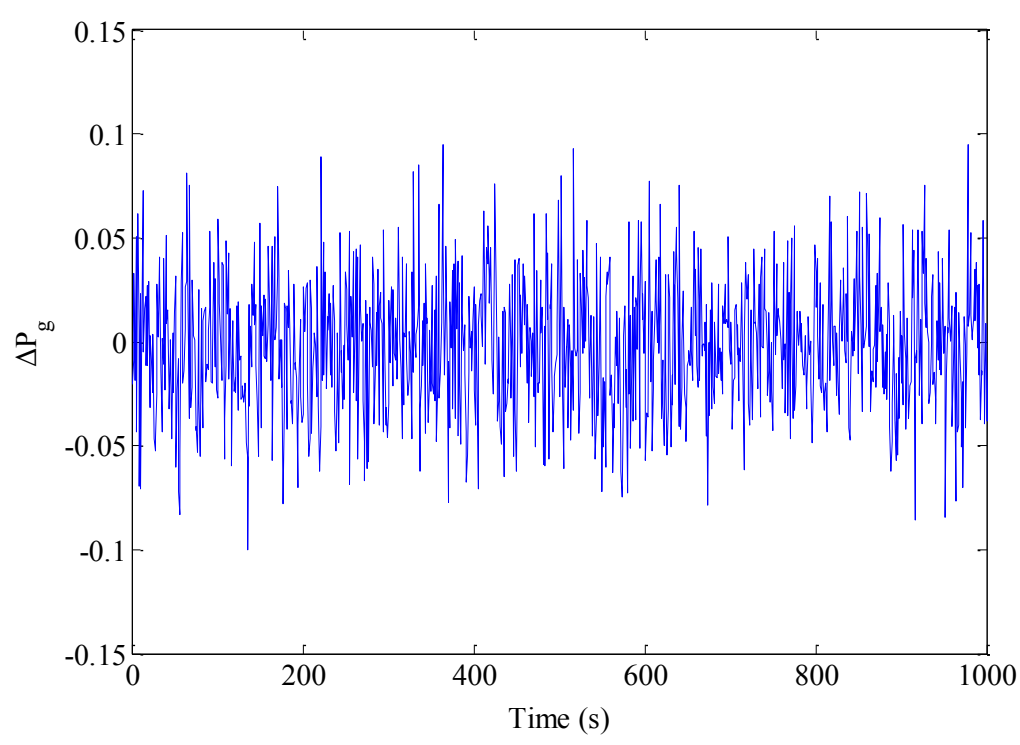

Fig. 3. A set of random generator electric power output.

From Table 1, the plant is operating in rated conditions. When the random generator electric power output is introduced into the PSHP, Figs. 4-6 show the actual three-dimensional dynamic responses of the system. 


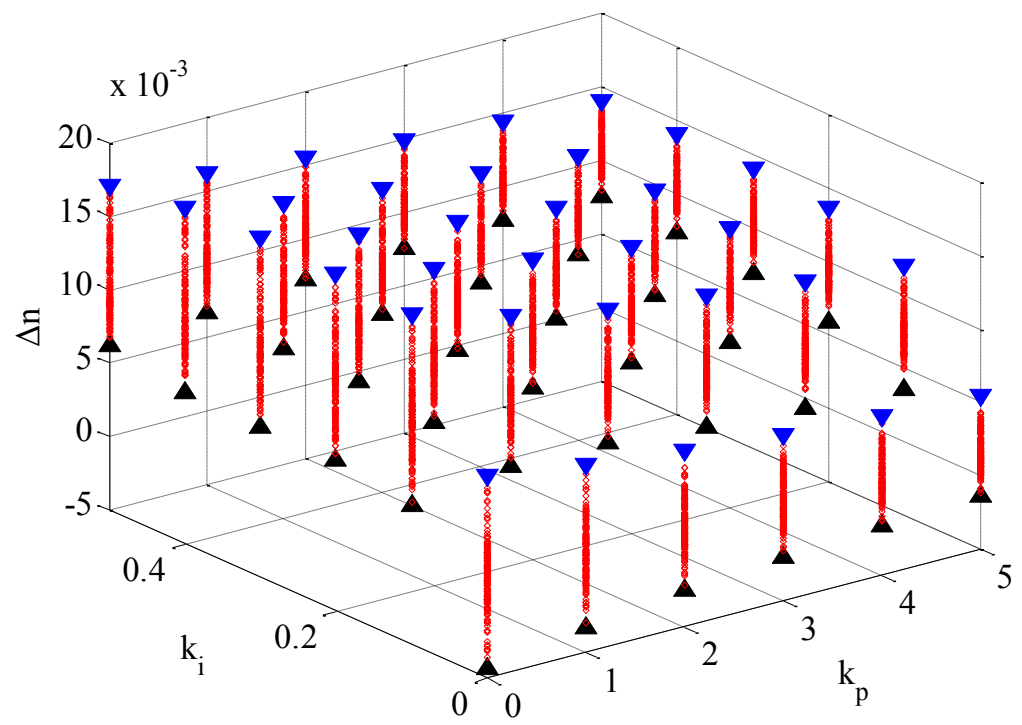

Fig. 4. Three-dimensional bifurcation diagram of the relative deviation of the speed.

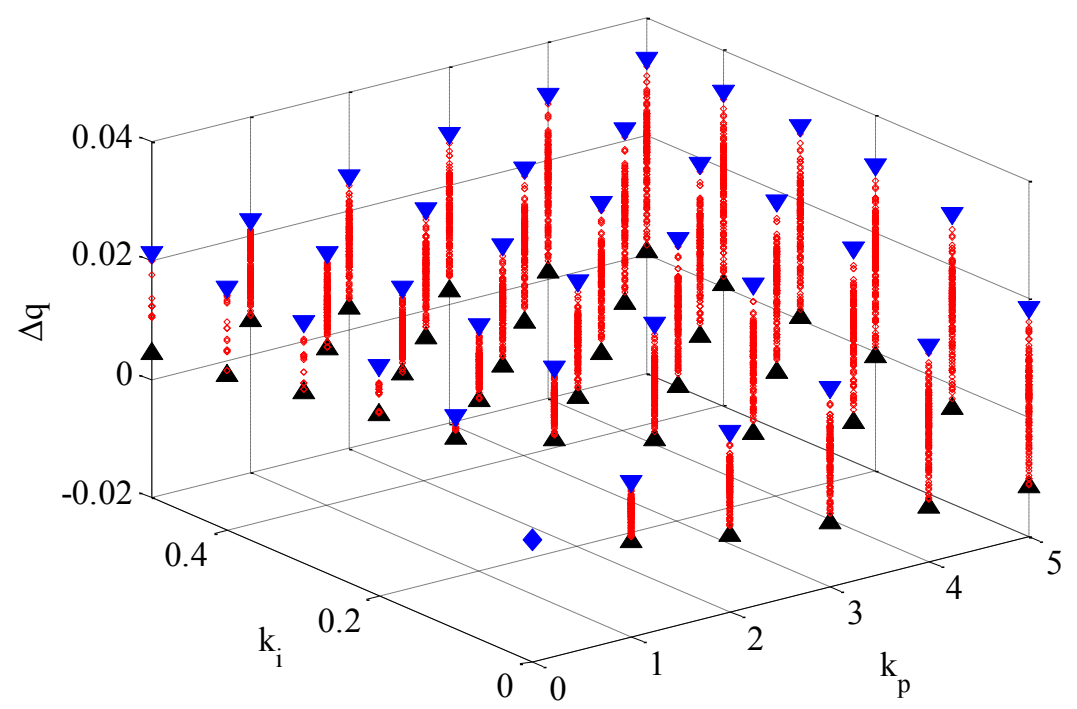

Fig. 5. Three-dimensional bifurcation diagram of the relative deviation of the flow through the turbine. 


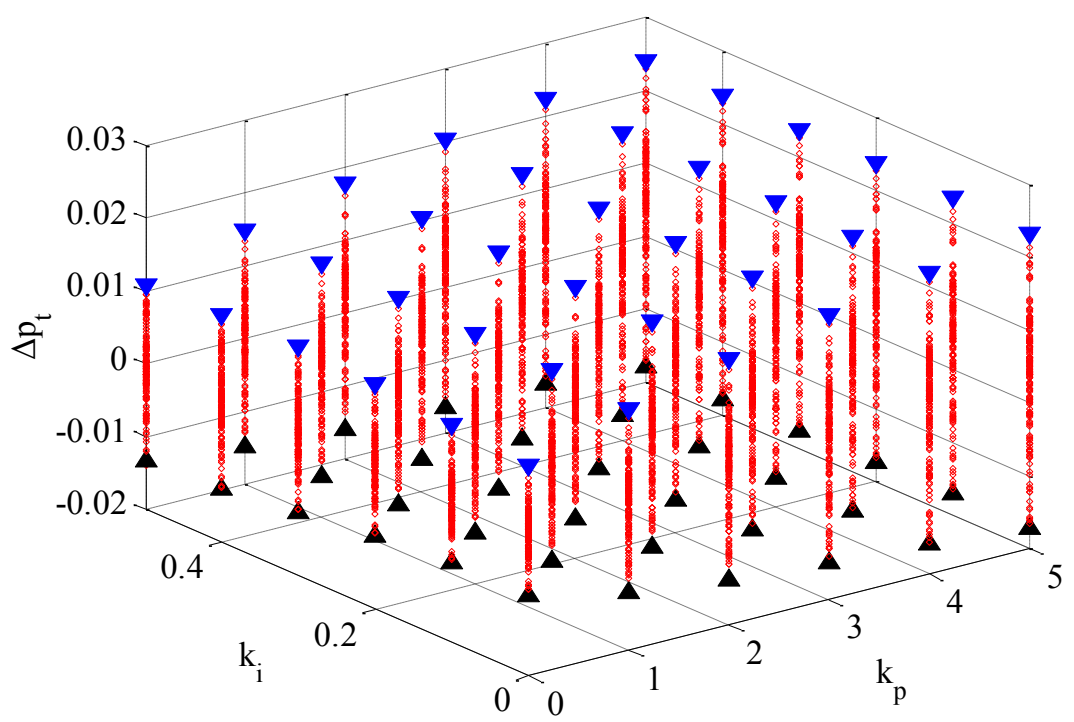

Fig. 6. Three-dimensional bifurcation diagram of the relative deviation of the mechanical power.

From Figs. 4-6, the settings of the governor PI have great impacts on the dynamic characteristics of the PSHP with the random power load. In addition, it is clear from the above three-dimensional bifurcation diagrams that the PI gains have different effects on different system parameters.

As shown in Fig. 4, the relative deviation of the speed varies from -0.005 to 0.018 when $0 \leq k_{i} \leq 0.5$ and $0 \leq k_{p} \leq 5$. In this region, the value of $k_{i}$ has little effect on the variation range of the relative deviation of the speed, while the increase of $k_{p}$ can reduce the variation range. It is worth noting that when $k_{i}$ is near 0 , compared with other groups, the variation range suddenly decreases by 0.01 . This means that the dynamic characteristics of the speed can be improved effectively, if $k_{i}=0$ and $k_{p}=5$.

The Fig. 5 shows the responses of the relative deviation of the flow through the turbine. For different PI gains, the relative deviation of the flow through the turbine varies from -0.018 to 0.035 . And the changing rule of the relative deviation of the flow is different from that of the speed. In Fig. 4, the relative deviation of the speed drops with the increase of the $k_{p}$. By contrast, the relative deviation of the flow through the turbine shows an upward trend with the $k_{p}$ increasing (Fig. 5). In addition, the relative deviation of the flow through the turbine falls steadily with the 
decrease of $k_{i}$. The relative deviation of the flow through the turbine has the minimum variation range when $k_{i}=0$ and $k_{p}=0$.

From Fig. 6, the effects of PI gains on the relative deviation of the mechanical power are similar to that on the relative deviation of the flow through the turbine. The fluctuation range of the relative deviation of the mechanical power experiences a dramatic decrease with the decreases of $k_{i}$ and $k_{p}$.

The responses of the relative deviation of the speed, flow through the turbine and mechanical power demonstrate that the PI gains are able to adjust the dynamic characteristic of the PSHP with the random power load. Furthermore, the optimal PI gains for the flow through the turbine and the mechanical power are different from that for the speed. The decrease of $k_{i}$ can improve the dynamic characteristics of the speed, the flow through the turbine and the mechanical power. The decrease of $k_{p}$ can also improve the dynamic quality of the flow through the turbine and the mechanical power, while it makes the speed unstable. The three-dimensional bifurcation diagrams of the relative deviation of the system parameters, as the method of qualitative research, present the different regulation laws of the PI gains for different system parameters. In order to further verify the regulation effect of the PI gains, simulation experiments are conducted with five representative groups of the PI gains, respectively. The five groups of the PI gains are

\begin{tabular}{cccccc}
\hline Group & 1 & 2 & 3 & 4 & 5 \\
$\left(k_{p}, k_{i}\right)$ & $(2.5,0.1)$ & $(2.5,0.25)$ & $(2.5,0.5)$ & $(0.1,0.25)$ & $(5,0.25)$ \\
\hline
\end{tabular}

In the numerical simulation, the effects of $k_{i}$ on the system parameters are studied through Groups 1, 2 and 3. For Groups 4, 2 and 5, they are selected to research the effect of $k_{p}$. 


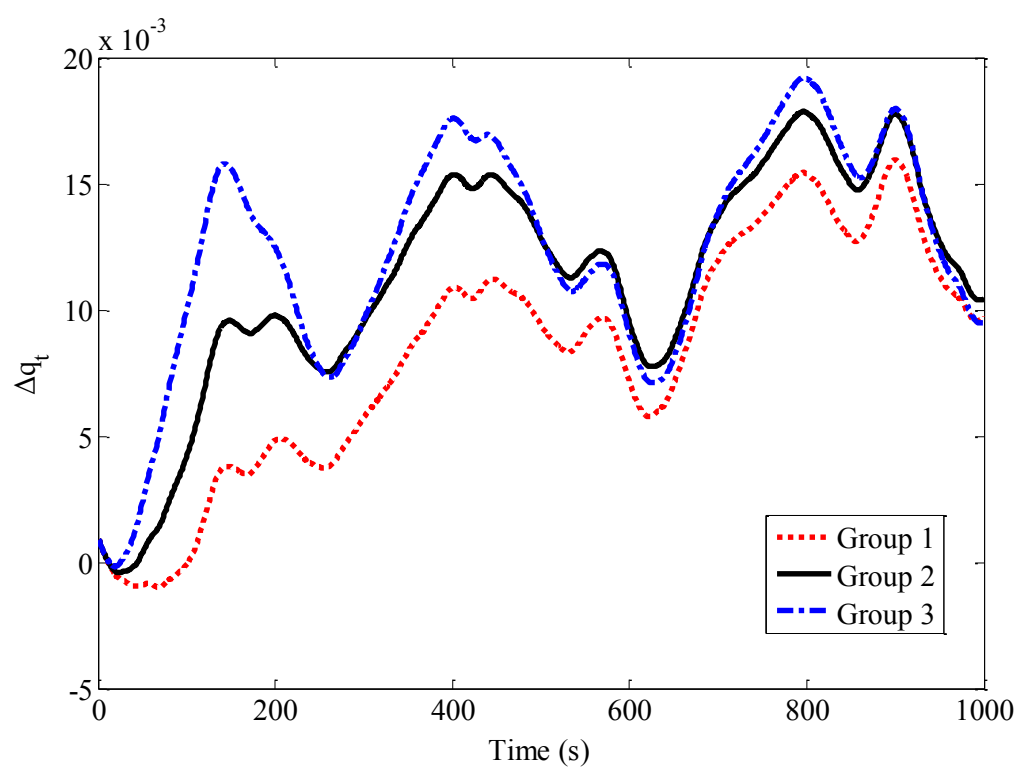

(a) Time waveforms with different $k_{i}$.

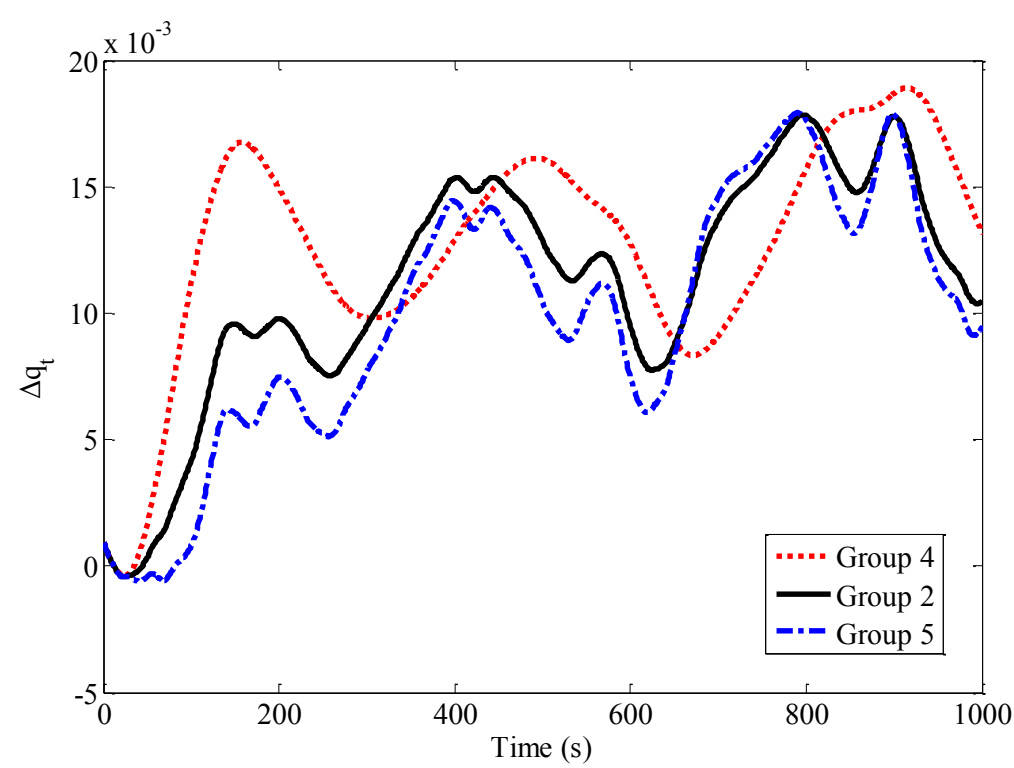

(b) Time waveforms with different $k_{p}$.

Fig. 7. Time waveforms of the relative deviation of the flow in the penstock with random power load.

As shown in Fig. 7, the relative deviation of the flow has the similar varying tendency in Groups 1-5. From Fig. 7(a), the relative deviation of the flow in the penstock in Group 3 is the highest throughout the period, reaching its peak at $19 \times 10^{-3}$ at 800 s. Moreover, the relative deviations of the flow in the penstock in Group 2 and 3 are consistently higher than that in Group 1. These results illustrate that the decrease of $k_{i}$ can improve the dynamic characteristics of the flow in the 
penstock. From Fig. 7(b), the relative deviation of the flow in Group 4 has the highest peak levels. The figures for Groups 2 and 5 are lower than that for Group 4 most of the time. The above results suggest that the flow in the penstock is becoming more stable with the increase of $k_{p}$.

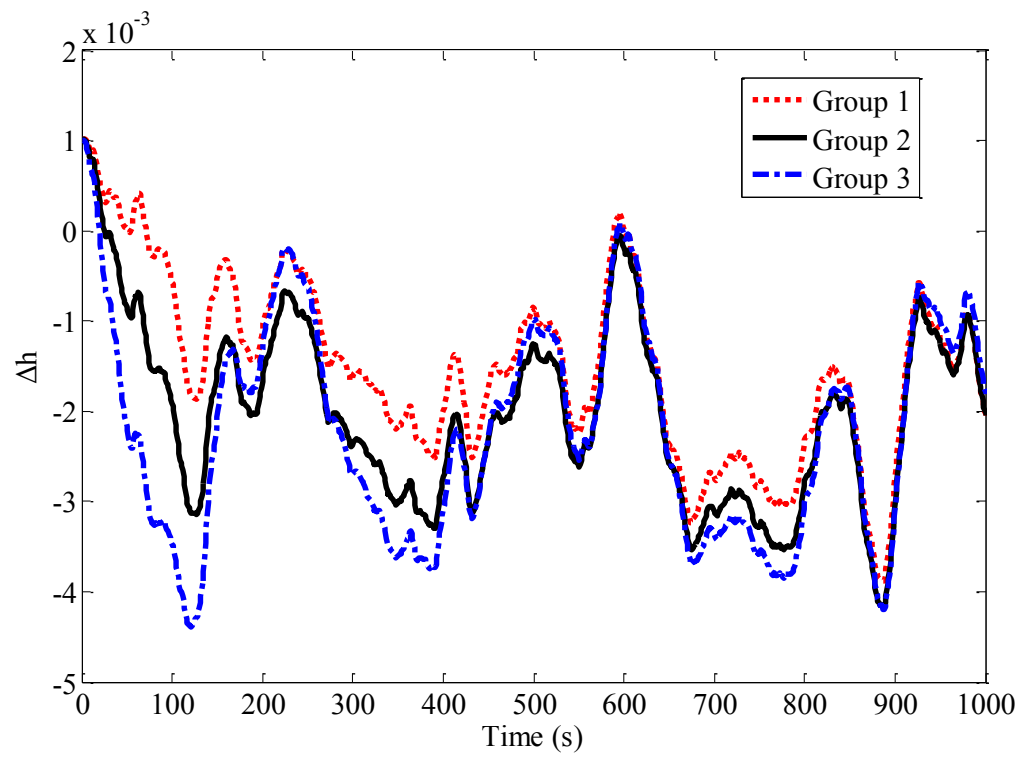

(a) Time waveforms with different $k_{i}$.

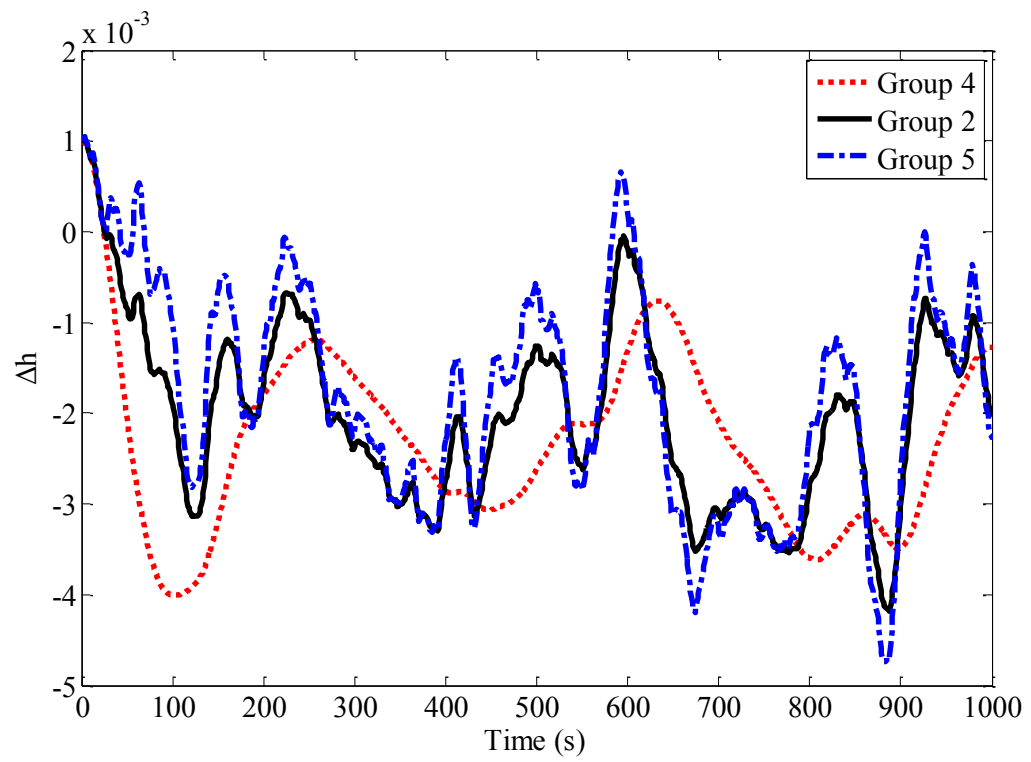

(b) Time waveforms with different $k_{p}$.

Fig. 8. Time waveforms of the relative deviation of the net head with random power load.

It can be seen from the Fig. 8 that the relative deviations of the net head experience dramatic fluctuations in Groups 1-5. It is worth noting that most of the net head is below zero over the period. From Fig. 8(a), the varying range of the net head is becoming more narrow with the decrease of $k_{i}$. In Fig. 8(b), the dynamic 
characteristics of the net head is improved with the decrease of $k_{p}$ because the figure for Group 4 is relative stable compared with that for Groups 2 and 5.

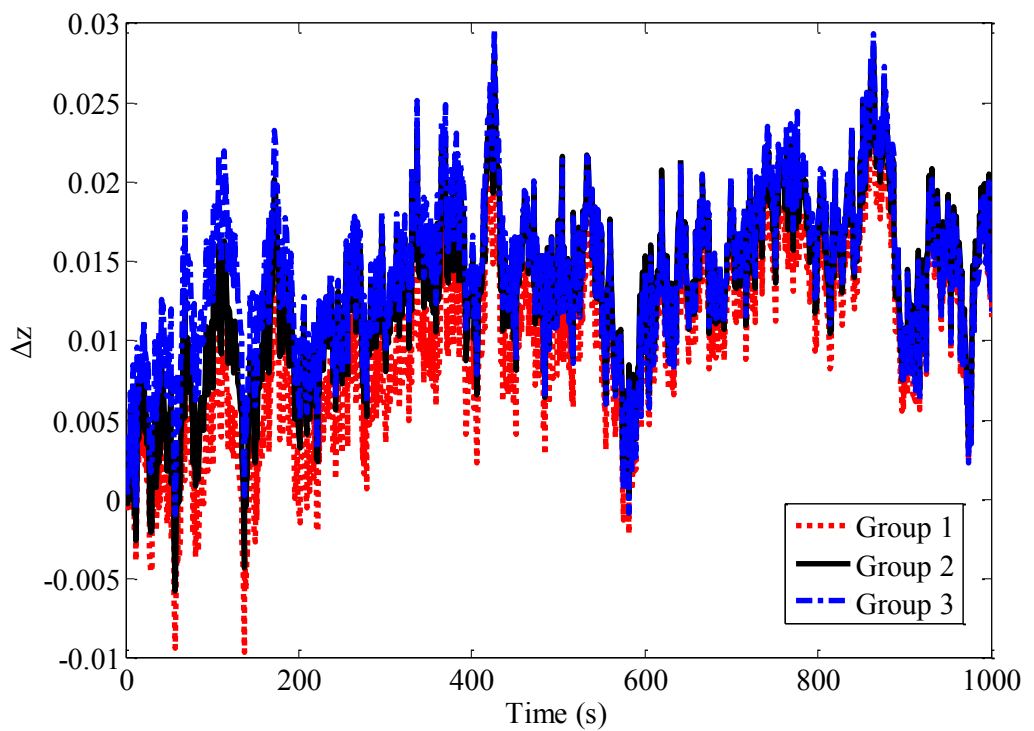

(a) Time waveforms with different $k_{i}$.

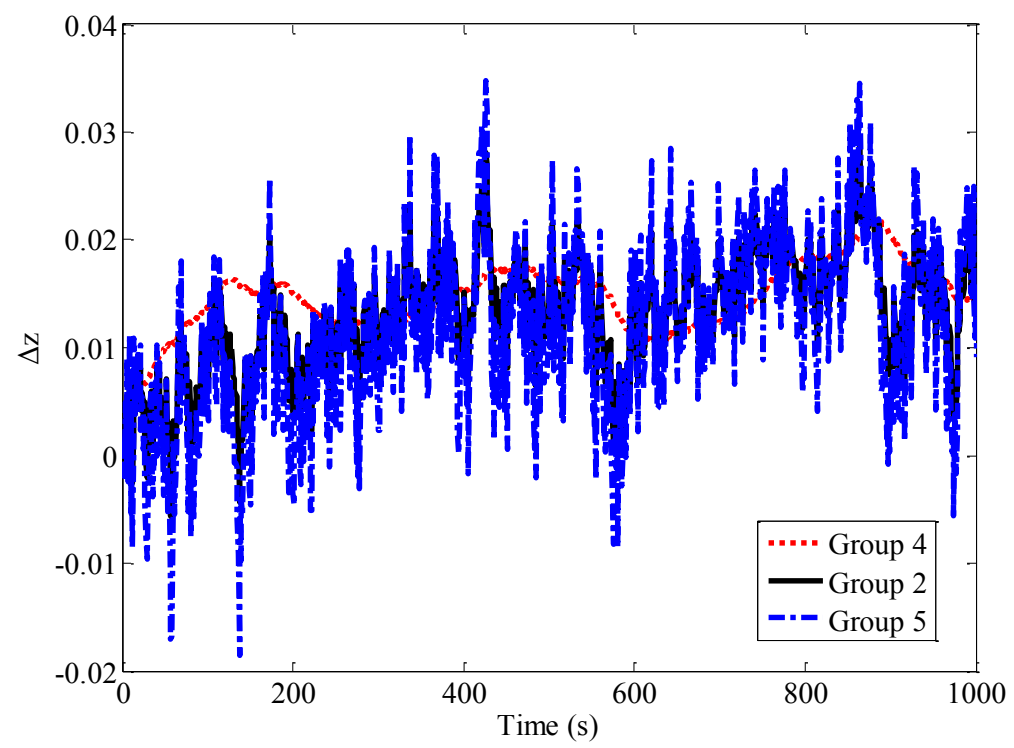

(b) Time waveforms with different $k_{p}$.

Fig. 9. Time waveforms of the relative deviation of the wicket gate position with random power load.

It is clear from the Fig. 9 that the relative deviation of the wicket gate position fluctuates significantly over the period. This means that the effect of the random power load is more remarkable for wick gate position than that for other system parameters. The wicket gate position presents stochastic fluctuation with different values of $k_{i}$. The quantity of Group 3 has the widest fluctuation range in Fig. 9(a). In 
addition, the figure for Group 2 fluctuates more violently than that for Group 1. The results illustrate that the wick gate position tends to fluctuate more widely with the $k_{i}$ increasing. It is clear from the Fig. 9(b) that the decrease of the $k_{p}$ is able to improve the dynamic characteristics of the wicket gate position.

The initial load can be denoted by the initial flow. In order to study the effect of the initial load on the dynamic characteristics of the PSHP, three groups of the initial flow are selected as follows:

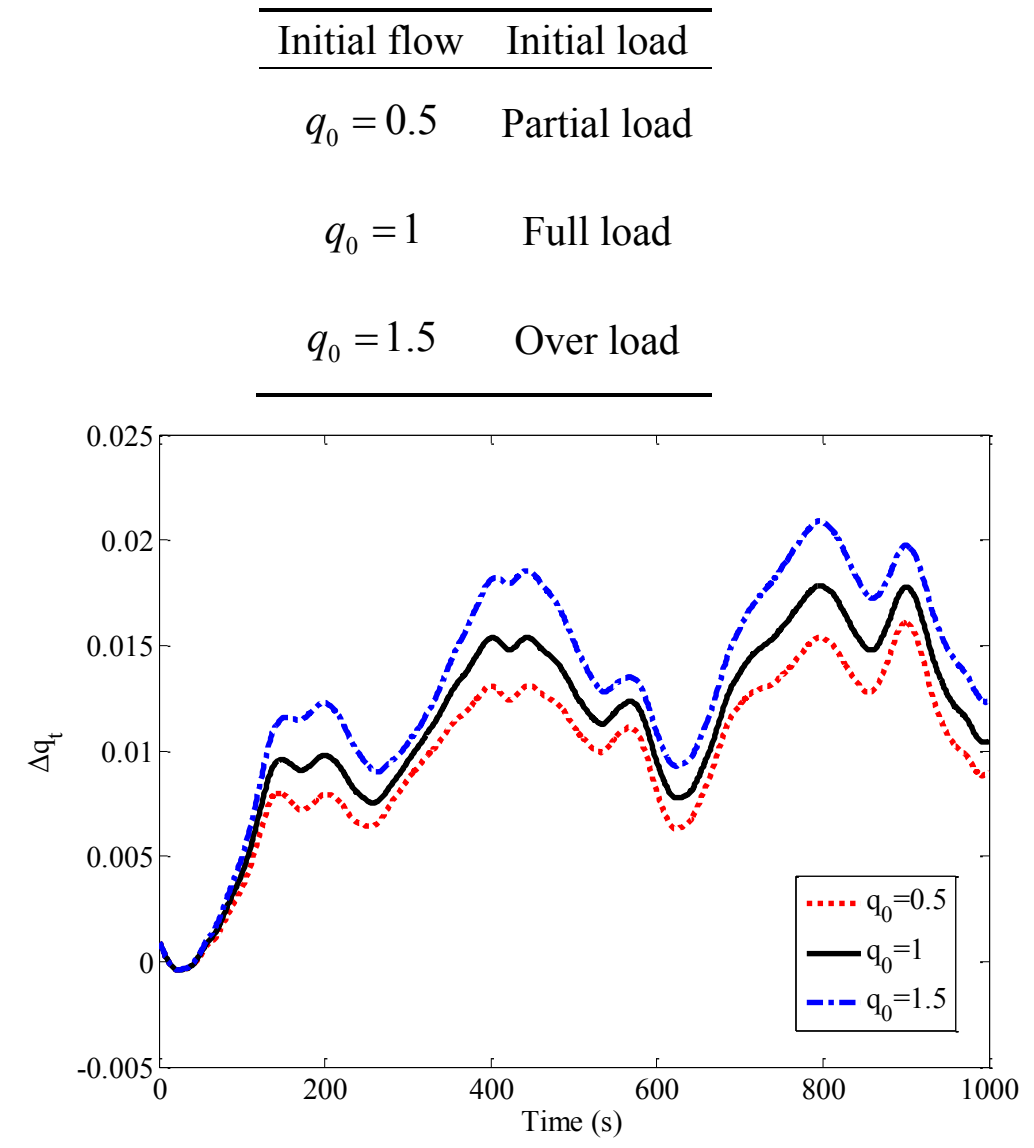

(a) Time waveforms of the flow in the penstock. 


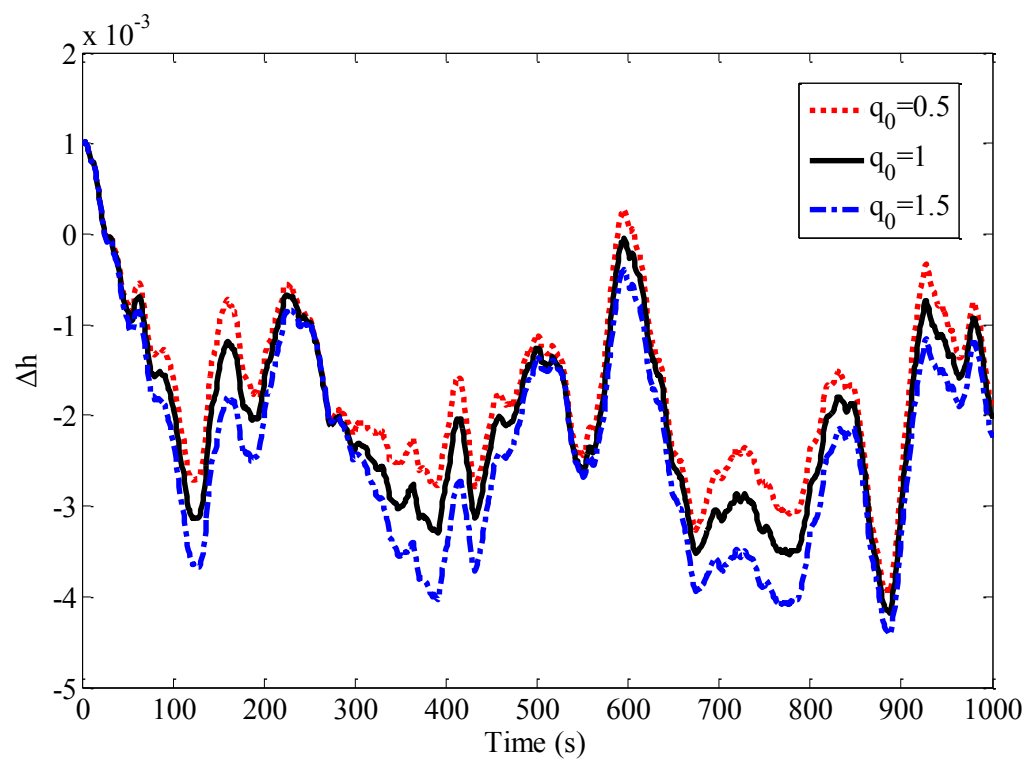

(b) Time waveforms of the net head.

Fig. 10. Time waveforms of the relative deviation of the flow in the penstock and the net head with different initial flows.

As shown in Fig. 10, the initial flow $q_{0}$ can regulate the fluctuation range of the flow in the penstock and net head. From Fig. 10(a), the relative deviation of the flow in the penstock for $q_{0}=1.5$ is consistently higher than for $q_{0}=1$ and $q_{0}=0.5$.

When $q_{0}=0.5$, the flow in the penstock has the minimum range in Fig. 10(a). From Fig. 10(b), the dynamic characteristics of the net head can be improved with the decrease of the initial flow. For different initial flows, the fluctuations of the flow in the penstock are more violent than that of the net head.

Finally, the simulation results demonstrate that the PI gains contribute significantly to regulating the dynamic characteristics of the PSHP with random power load. In addition, the initial load can also influence the stability of the PSHP during the process.

\section{Conclusions}

In this paper, the effects of PI gains and initial load on the dynamic characteristics of the PSHP with random power load have been analyzed from the point of view of dynamics.

The simulation results show that the PI gains have different influences on 
different system parameters. In generating mode, the PI gains are able to improve the dynamic characteristics of the PSHP with random power load. It is important to note that the decrease of $k_{i}$ is able to increase the stability of the system, while the decrease of $k_{p}$ has the opposite effect on the speed of the PSHP. Additionally, the simulation results demonstrate that the dynamic characteristics of the PSHP can be improved with smaller initial load.

\section{Acknowledgements}

This work was supported by the scientific research foundation of National Natural Science Foundation-Outstanding Youth Foundation (51622906), National Science Foundation (51479173), Fundamental Research Funds for the Central Universities (201304030577), Scientific research funds of Northwest A\&F University (2013BSJJ095), the scientific research foundation on water engineering of Shaanxi Province (2013slkj-12), the Science Fund for Excellent Young Scholars from Northwest A\&F University and Shaanxi Nova program (2016KJXX-55).

\section{References}

[1] E. Egusquiza, C. Valero, A. Presas, X. X. Huang, A. Guardo, U. Seidel, Analysis of the dynamic response of pump-turbine impellers. Influence of the rotor, Mech. Syst. Signal Proc. 68-69 (2016) 330-341.

[2] F. Botero, V. Hasmatuchi, S. Roth, M. Farhat, Non-intrusive detection of rotating stall in pump-turbines, Mech. Syst. Signal Proc. 48 (1-2) (2014) 162-173.

[3] T. Krappel, H. Kuhlmann, O. Kirschner, A. Ruprecht, S. Riedelbauch, Validation of an IDDES-type turbulence model and application to a Francis pump turbine flow simulation in comparison with experimental results, Int. J. Heat Fluid Flow 55 (2015) 167-179.

[4] A. Presas, D. Valentin, E. Egusquiza, C. Valero, U. Seidel, On the detection of natural frequencies and mode shapes of submerged rotating disk-like structures from the casing, Mech. Syst. Signal Proc. 60-61 (2015) 547-570. 
[5] T. Ma, H. X. Yang, L. Lu, J. Q. Peng, Optimal design of an autonomous solar-wind-pumped storage power supply system, Appl. Energy 160 (2015) 728-736.

[6] P. Pennacchi, S. Chatterton, A. Vania, Modeling of the dynamic response of a Francis turbine, Mech. Syst. Signal Proc. 29 (2012) 107-119.

[7] P. Pennacchi, P. Borghesani, S. Chatterton, A cyclostationary multi-domain analysis of fluid instability in Kaplan turbines, Mech. Syst. Signal Proc. 60-61 (2015) 375-390.

[8] D. Y. Li, H. J. Wang, G. M. Xiang, R. Z. Gong, X. Z. Wei, Z. S. Liu, Unsteady simulation and analysis for hump characteristics of a pump turbine model, Renew. Energy 77 (2015) 32-42.

[9] V. Hasmatuchi, M. Farhat, S. Roth, F. Botero, F. Avellan, Experimental Evidence of Rotating Stall in a Pump-Turbine at Off-Design Conditions in Generating Mode, J. Fluids Eng.-Trans. ASME 133(5) (2011) 051104.

[10] I. Samora, V. Hasmatuchi, C. Munch-Alligne, M. J. Franca, A. J. Schleiss, H. M. Ramos, Experimental characterization of a five blade tubular propeller turbine for pipe inline installation, Renew. Energy 95 (2016) 356-366.

[11] J. I. Sarasua, J. I. Perez-Diaz, J. R. Wilhelmi, J. A. Sanchez-Fernandez, Dynamic response and governor tuning of a long penstock pumped-storage hydropower plant equipped with a pump-turbine and a doubly fed induction generator, Energy Conv. Manag. 106 (2015) 151-164.

[12] F. Petrakopulou, A. Robinson, M. Loizidou, Simulation and analysis of a stand-alone solar-wind and pumped-storage hydropower plant, Energy 96 (2016) 676-683.

[13] B. B. Xu, F. F. Wang, D. Y. Chen, H. Zhang, Hamiltonian modeling of multi-hydro-turbine governing systems with sharing common penstock and nonlinear dynamic analyses under shock load, Energy Conv. Manag. 108 (2016) 478-487.

[14] R. Susan-Resiga, S. Muntean, V. Hasmatuchi, I. Anton, F. Avellan, Analysis and prevention of vortex breakdown in the simplified discharge cone of a francis turbine, J. Fluids Eng.-Trans. ASME 132(5) (2010) 051102.

[15] W. C. Guo, J. D. Yang, W. J. Yang, J. P. Chen, Y. Teng, Regulation quality for frequency response of turbine regulating system of isolated hydroelectric power plant with surge tank, Int. J. Electr. Power Energy Syst. 73 (2015) 528-538.

[16] Y. Pannatier, B. Kawkabani, C. Nicolet, J. J. Simond, A. Schwery, P. Allenbach, Investigation 
of Control Strategies for Variable-Speed Pump-Turbine Units by Using a Simplified Model of the Converters, IEEE Trans. Ind. Electron. 57(9) (2010) 3039-3049.

[17] X. X. Zhang, Y. G. Cheng, L. S. Xia, J. D. Yang, Z. D. Qian, Looping Dynamic Characteristics of a Pump-Turbine in the S-shaped Region During Runaway, J. Fluids Eng.-Trans. ASME 138(9) (2016) 091102.

[18] H. H. Li, D. Y. Chen, H. Zhang, F. F. Wang, D. D. Ba, Nonlinear modeling and dynamic analysis of a hydro-turbine governing system in the process of sudden load increase transient, Mech. Syst. Signal Proc. 80 (2016) 414-428.

[19] S. Barbarelli, M. Amelio, G. Florio, Predictive model estimating the performances of centrifugal pumps used as turbines, Energy 107 (2016) 103-121.

[20] W. Zeng, J. D. Yang, J. H. Hu, J. B. Yang, Guide-Vane Closing Schemes for Pump-Turbines Based on Transient Characteristics in S-shaped Region, J. Fluids Eng.-Trans. ASME 138(5) (2016) 051302.

[21] W. Zeng, J.D. Yang, W.J. Yang, Instability analysis of pumped-storage stations under no-load conditions using a parameter-varying model, Renew. Energy 90 (2016) 420-429.

[22] S. Alligne, C. Nicolet, Y. Tsujimoto, F. Avellan, Cavitation surge modelling in Francis turbine draft tube, J. Hydraul. Res. 52(3) (2014) 399-411.

[23] C. Nicolet, B. Greiveldinger, J. J. Herou, B. Kawkabani, P. Allenbach, J. J. Simond, High-order modeling of hydraulic power plant in islanded power network, IEEE Trans. Power Syst. 22(4) (2007) 1870-1880.

[24] T. M. Premkumar, P. Kumar, D. Chatterjee, Cavitation Characteristics of S-Blade Used in Fully Reversible Pump-Turbine, J. Fluids Eng.-Trans. ASME 136(5) (2014) 051101.

[25] J. J. Zhou, A. Vacca, P. Casoli, A novel approach for predicting the operation of external gear pumps under cavitating conditions, Simul. Model. Pract. Theory 45 (2014) 35-49.

[26] Y. Zeng, L. X. Zhang, Y. K. Guo, J. Qian, C. L. Zhang, The generalized Hamiltonian model for the shafting transient analysis of the hydro turbine generating sets, Nonlinear Dyn. 76 (2014) 1921-1933.

[27] Z.G. Zuo, S.H. Liu, Y.K. Sun, Y.L. Wu, Pressure fluctuations in the vaneless space of High-head pump-turbines-A review, Renew. Sust. Energ. Rev. 41 (2015) 965-974.

[28] J. I. Perez-Diza, J. I. Sarasua, J. R. Wihelmi, Contribution of a hydraulic short-circuit pumped-storage power plant to the load-frequency regulation of an isolated power system, Int. J. Electr. Power Energy Syst. 62 (2014) 199-211.

[29] IEEE Working Group. Hydraulic turbine and turbine control models for system dynamic studies. IEEE Trans Power Syst 1992; 7: 167-179.

[30] N. Kishor, R. P. Saini, S. P. Singh, A review on hydropower plant models and control, Renew. Sust. Energ. Rev. 11 (2007) 776-796. 
[31] G. Martínez-Lucas, J. I. Sarasúa, J. A. Sánchez-Fernández, J. R. Wilhelmi, Power-frequency control of hydropower plants with long penstocks in isolated systems with wind generation, Renew. Energy 83 (2015) 245-255.

[32] H. Hanachi, J. Liu, A. Banerjee, Y. Chen, Sequential state estimation of nonlinear/non-Gaussian systems with stochastic input for turbine degradation estimation, Mech. Syst. Signal Proc. 72-73 (2016) 32-45.

[33] H. Verdejo, W. Kliemann, L. Vargas, C. Becker, Stability region and radius in electric power systems under sustained random perturbations, Int. J. Electr. Power Energy Syst. 73 (2015) 725-733.

[34] C. Y. Chung, K. W. Wang, C. T. Tse, R. Niu, Power-system stabilizer (PSS) design by probabilistic sensitivity indexes (PSIs), IEEE Trans. Power Syst. 17(3) (2002) 688-693. 